\title{
EFFECTS OF SHOES ON KINETICS AND KINEMATICS OF THE SQUASH FORWARD LUNGE IN MALE PLAYERS
}

\author{
Jonathan Sinclair' ${ }^{1}$ Lindsay Bottoms², Paul John Taylor ${ }^{3}$, and Khizar Mahmood ${ }^{1}$ \\ ${ }^{1}$ Centre for Applied Sport and Exercise Sciences, Faculty of Health and Wellbeing, \\ University of Central Lancashire, UK \\ ${ }^{2}$ Department of Human and Environmental Sciences, School of Life and Medical Sciences, \\ University of Hertfordshire, UK \\ ${ }^{3}$ School of Psychology, University of Central Lancashire, UK
}

Original scientific paper

UDC: $796.346: 612$

\begin{abstract}
:
Squash is associated with a high incidence of chronic injuries. Currently there is a trend in many sports for players to select minimalist footwear. The aim of the current investigation was to examine the effects of squashspecific, running shoes and minimalist footwear on the kinetics and 3-D kinematics of the lunge movement in squash players. Twelve male squash players performed lunge movements whilst wearing minimalist, running shoe and squash-specific footwear. 3-D kinematics of the lower extremities were measured using an eightcamera motion analysis system alongside kinetic and tibial acceleration information which were obtained using a force platform and an accelerometer. Differences between footwear were examined using one-way repeated measures ANOVA. The results show firstly that loading rate parameters were significantly greater in the minimalist (average $=85.36 \mathrm{~B} . \mathrm{W} / \mathrm{s}$ and instantaneous $=179.09 \mathrm{~B} . \mathrm{W} / \mathrm{s}$ ) footwear in relation to the squashspecific (average $=38.66 \mathrm{~B} . \mathrm{W} / \mathrm{s}$ and instantaneous $=50.73 \mathrm{~B} . \mathrm{W} / \mathrm{s}$ ) and running footwear (average $=37.62 \mathrm{~B} . \mathrm{W} / \mathrm{s}$ and instantaneous $=48.14 \mathrm{~B} . \mathrm{W} / \mathrm{s}$ ). In addition, tibial acceleration parameters were also significantly greater in the minimalist (peak tibial acceleration $=8.45 \mathrm{~g}$ and tibial acceleration slope $=422.28 \mathrm{~g} / \mathrm{s}$ ) footwear in relation to the squash-specific (peak tibial acceleration $=4.33 \mathrm{~g}$ and tibial acceleration slope $=182.57 \mathrm{~g} / \mathrm{s}$ ) and running footwear (peak tibial acceleration $=4.81 \mathrm{~g}$ and tibial acceleration slope $=226.72 \mathrm{~g} / \mathrm{s}$ ). The significant increase in impact loading in the minimalist footwear therefore suggests this type of shoe may place squash players at an increased risk of developing impact-related chronic injuries.
\end{abstract}

Key words: biomechanics, footwear, squash

\section{Introduction}

Squash is a quickly expanding sport (Eime, Zazryn, \& Finch, 2003); there are over 15 million players worldwide from a total of 135 participating countries (Meyer, van Niekerk, Prinsloo, Steenkamp, \& Louw, 2009). It is a competitive sport that places high demands on both aerobic and anaerobic systems of players (Finch \& Eime, 2001). Squash is characterized by a series of rapid accelerations/ decelerations, comprised primarily of lunges and side stepping motions (Vuckovic \& James, 2010). The analysis of squash game dynamics has shown that players are required to be active for up to $70 \%$ of their time on court (Clavisi \& Finch, 2000).

Speed and repetitive nature of squash has been shown to place players at risk from injury. Chronic injuries are common in both competitive and recreational squash players (Berson, Rolnick, Ramos, \& Thornton, 1981; Clavisi \& Finch, 2000). The preva- lence of injuries in squash players has been shown to be $45 \%$ (Berson, et al., 1981). Chronic musculoskeletal pathologies in squash players can occur in both upper and lower limbs and also the lower back (Finch \& Eime, 2001). Chronic injuries to the lower extremities are the most common squash-related injuries, with the knee and ankle joints being the most frequently injured sites (Finch \& Eime, 2001).

Using appropriate footwear, it has been proposed that athletes may be able to control the incidence of chronic injuries (Shorten, 1993). However, there is a lack of published research investigating the effects of different footwear on the parameters linked to the aetiology of injury development in squash-specific movements. Currently, there is a trend in court based sports including squash, for players to select minimalist footwear in lieu of sport-specific footwear (Sinclair, Chockalingam, Naemi, \& Vincent, 2015) although the clinical efficacy of minimalist 
footwear has not yet been established for squashspecific motions.

The biomechanics of minimalist footwear has been examined extensively in a range of other sports with conflicting findings. The majority of this work has been conducted using runners. Some research has shown that impact loading and forces at specific musculoskeletal structures are reduced when running in minimalist footwear (Bonacci, Saunders, Hicks, Rantalainen, Vicenzino, \& Spratford, 2013; Bonacci, Vicenzino, Spratford, \& Collins, 2014; Squadrone \& Gallozzi 2009), whereas some has shown the opposite (Firminger \& Edwards, 2016; Paquette, Zhang, \& Baumgartner, 2013; Sinclair, Greenhalgh, Edmundson, Brooks, \& Hobbs, 2013; Sinclair, Hobbs, Currigan, \& Taylor, 2013). Sinclair, McCarthy, Bentley, Hurst, \& Atkins (2015) have conducted the only study investigating the effects of minimalist footwear in court sports. This investigation compared the effects of minimalist and netballspecific footwear on the kinetics and kinematics of three netball-specific movements: jog, $45^{\circ}$ cut and vertical jump. Their findings confirmed in the jog and $45^{\circ}$ cut movements that vertical loading rate and peak ankle eversion was significantly larger in the minimalist footwear. No differences were shown in the vertical jump.

The lunge movement is used frequently in competitive squash and the ability to quickly execute a controlled lunge is a key aspect of the game (Cronin, McNair, \& Marshall, 2003). The lunge movement has been shown to be associated with high impact forces (Sinclair, Bottoms, Taylor, \& Greenhalgh, 2010), indicating the propensity for injury as a function of this movement is high in squash players. Stacoff et al. (1988) propose that the primary function of athletic footwear is to provide shock attenuation. Clavisi and Finch (2002) have cited inappropriate footwear as a potential contributor to the development of lower extremity injures in squash players.

There is currently a paucity of research regarding the effects of different footwear on the biomechanics of the lunge movement. Sinclair et al. (2010) examined tibial accelerations in fencing, court-specific and running footwear during the lunge. This study showed that tibial accelerations were significantly reduced in court and running footwear compared to fence-specific shoes. Geil (2002) measured plantar pressures when wearing fencing and court footwear during the lunge. They showed that the court footwear significantly reduced peak plantar pressure at the front and rear aspects of the foot. However, there is currently no published work investigating the effects of squash footwear during the lunge movement in squash players, indicating that there is no quantitative data available to provide information regarding the most appropriate footwear for squash players to attenuate their risk of lower extremity injuries.
The aim of the current investigation was therefore to examine the effects of squash-specific, running shoes and minimalist footwear on the kinetics and 3-D kinematics of the lunge movement in squash players. This work may provide important information regarding the selection of appropriate footwear for the reduction of chronic injuries in squash players. This study tests the hypothesis that the minimalist footwear will be associated with increased impact loading in relation to the squashspecific and running shoes.

\section{Methodology}

\section{Participants}

A sample of twelve male participants (age 21.59 \pm 2.28 years; body height $1.74 \pm 0.07 \mathrm{~m}$; body mass $68.12 \pm 4.54 \mathrm{~kg}$ ) volunteered to take part in the current investigation. Participants were all competitive university level squash players, who had a minimum of 4 years of playing experience and 2 years of competitive experience. Ethical approval for this project was obtained from the University ethics committee, and each participant provided a written consent in accordance with the Declaration of Helsinki.

\section{Experimental footwear}

The experimental footwear used during the current investigation consisted of a running shoe (New balance 1260 v2), minimalist (Vibram fivefingers, ELX) and squash shoe (Asics Mens GEL Rocket 7 Indoor), (shoe size 8-10 UK men's). In accordance with the protocol of Sinclair et al. (2015), participants were also asked about their preferred footwear choice after all trials were completed.

\section{Procedure}

Participants completed five lunges in each footwear condition. Following each lunge participants were required to return to a starting point, which was pre-determined before the commencement of data collection by having participants determine their habitual distance when executing a lunging forehand. This allowed the lunge distance to be maintained for each condition. Participants were also required to contact a force platform (Kistler, Kistler Instruments Ltd., Alton, Hampshire) embedded into the floor of the biomechanics laboratory with their right (lead) foot. The force platform sampled at $1000 \mathrm{~Hz}$. The lunge movement was considered to begin at the point of foot contact with the dominant (right) leading foot, this was taken as the point at which $>20 \mathrm{~N}$ of vertical force was applied to the force platform. The end of the lunge movement was taken as the point of maximum flexion of the right knee. The order that participants performed in each footwear condition was undertaken in a counterbalanced manner. 
Kinematic information was obtained using an eight camera optoelectric motion capture system (Qualisys Medical AB, Goteburg, Sweden) using a capture frequency of $250 \mathrm{~Hz}$. Kinematics, force platform and tibial acceleration data were synchronized using an analogue to digital interface board. To model the lower extremity segments in six degrees of freedom the calibrated anatomical systems technique was utilized (Cappozzo, Catani, Leardini, Benedeti, \& Della, 1995). To define the segment co-ordinate axes of the right: foot, shank and thigh, retroreflective markers were placed unilaterally onto the $1^{\text {st }}$ metatarsal, $5^{\text {th }}$ metatarsal, calcaneus, medial and lateral malleoli, medial and lateral epicondyles of the femur. To define the pelvis segment, markers were posited onto the anterior (ASIS) and posterior (PSIS) superior iliac spines. The centres of the ankle and knee joints were delineated as the mid-point between the malleoli and femoral epicondyle markers, whereas the hip joint centre was obtained using the positions of the ASIS markers (Bell, Brand, \& Pedersen, 1989). The Z (transverse) axis was oriented vertically from the distal segment end to the proximal segment end. The Y (coronal) axis was oriented in the segment from posterior to anterior. Finally, the X (sagittal) axis orientation was determined using the right hand rule and was oriented from medial to lateral. Carbon fibre tracking clusters were positioned onto the shank and thigh segments. The foot was tracked using the $1^{\text {st }}$ metatarsal, $5^{\text {th }}$ metatarsal and calcaneus markers and the pelvis using the ASIS and PSIS markers. Static calibration trials were obtained allowing for the anatomical markers to be referenced in relation to the tracking markers / clusters.

To measure axial accelerations at the tibia, an accelerometer (Biometrics ACL 300, Gwent United Kingdom) sampling at $1000 \mathrm{~Hz}$ was used. The device was attached onto a piece of lightweight carbon-fibre material using the protocol outlined by Sinclair et al., (2010). The accelerometer was strapped securely to the distal anterio-medial aspect of the tibia in alignment with its longitudinal axis $0.08 \mathrm{~m}$ above the medial malleolus. Strong nonstretch adhesive tape was placed over the device and leg to avoid overestimating the acceleration due to tissue artefact.

\section{Data processing}

Retroreflective markers were digitized using Qualisys Track Manager in order to identify appropriate markers then exported as C3D files. 3-D kinematics were quantified using Visual 3-D (C-Motion Inc, Germantown, MD, USA) after which marker displacement data were smoothed using a lowpass Butterworth $4^{\text {th }}$ order zero-lag filter at a cut off frequency of $12 \mathrm{~Hz}$. 3-D kinematics were calculated using an XYZ cardan sequence. All kinematic waveforms were normalized to $100 \%$ of the lunge movement. Discrete 3-D kinematic measures from the ankle and tibia which were extracted for statistical analysis, were as follows: 1) angle at footstrike, 2) peak angle, and 3) relative range of motion (representing the angular displacement from foot strike to peak angle).

Forces were reported in bodyweights (BW) to allow normalisation of the data among participants. Average loading rate, instantaneous loading rate, peak impact force and time to peak impact were calculated from the force plate data. The impact peak was determined as the peak force in the first $25 \%$ of the lunge movement. Average loading rate (BW/s) was calculated by dividing the impact peak magnitude by the time to the impact peak. Instantaneous loading rate $(\mathrm{BW} / \mathrm{s})$ was quantified as the maximum increase in vertical force between frequency intervals.

The tibial acceleration signal was filtered using a $60 \mathrm{~Hz}$ Butterworth zero lag $4^{\text {th }}$ order low pass filter to prevent any resonance effects on the acceleration signal. Peak tibial acceleration (g) was defined as the highest positive acceleration peak measured between the footstrike and maximum knee flexion. Tibial acceleration slope $(\mathrm{g} / \mathrm{s})$ was quantified by dividing the peak tibial acceleration by the time taken from the foot strike to peak tibial acceleration.

\section{Statistical analyses}

Kinetic, tibial acceleration and 3-D kinematic measures (outlined previously) were calculated for each footwear condition for each participant and an ensemble mean and standard deviation were calculated for the group. Differences between footwear were examined using one-way repeated measures ANOVA with significance accepted at the $\mathrm{p} \leq .05$ level. Post-hoc pairwise comparisons were conducted on all significant main effects using a Bonferroni adjustment. Effect sizes were calculated for each significant main effect using partial $\operatorname{eta}^{2}\left(p \eta^{2}\right)$. The normality assumption was calculated using a Shapiro-Wilk test, which confirmed that all data were normally distributed. Finally, a Chi-square $\left(\chi^{2}\right)$ test was used to examine participants subjectively preferred footwear. All statistical procedures were conducted using SPSS v22.0 (SPSS Inc. Chicago, USA).

\section{Results}

Figure 1 and Tables 1-4 present the mean \pm standard deviation kinetics, kinematics and tibial accelerations as a function of footwear.

\section{Footwear preference}

The Chi-squared test was significant $\left(\chi^{2}=16.55\right.$, $\mathrm{p}<.05)$ : ten participants preferred the running shoe, one preferred the minimalist footwear and one preferred the squash shoe. 


\section{Kinetics}

A significant main effect $\left(\mathrm{F}_{(2,22)}=6.94, \mathrm{p}<.05\right.$, $\left.\mathrm{p \eta}^{2}=0.41\right)$ was observed for time to impact peak. Post-hoc analysis showed that time to impact peak was significantly shorter in the minimalist footwear compared to the squash $(\mathrm{p}=.04)$ and running $(\mathrm{p}=.003)$ footwear. In addition, a significant main effect $\left(\mathrm{F}_{(2,22)}=18.87, \mathrm{p}<.05, \mathrm{p \eta}^{2}=0.65\right)$ was found for average loading rate. Post-hoc analysis showed that average loading rate was significantly greater in the minimalist footwear compared to the squash $(\mathrm{p}=.001)$ and running $(\mathrm{p}=.001)$ footwear. A signi- ficant main effect $\left(\mathrm{F}_{(2,22)}=23.24, \mathrm{p}<.05, \mathrm{p} \eta^{2}=0.70\right)$ was shown for instantaneous loading rate. Posthoc analysis showed that instantaneous loading rate was significantly greater in the minimalist footwear compared to the squash $(\mathrm{p}=.001)$ and running $(\mathrm{p}=.0004)$ footwear.

\section{Tibial accelerations}

There was a significant main effect $\left(\mathrm{F}_{(2,22)}=\right.$ 15.92, $\left.\mathrm{p}<.05, \mathrm{p}^{2}=0.61\right)$ for peak tibial acceleration. Post-hoc analysis showed that tibial accelerations were significantly greater in the minimalist

Table 1. Kinetic, temporal and tibial acceleration parameters as a function of footwear

\begin{tabular}{|c|c|c|c|c|c|c|c|}
\hline & \multicolumn{2}{|c|}{ Running shoe } & \multicolumn{2}{|c|}{ Minimalist } & \multicolumn{2}{|c|}{ Squash footwear } & \\
\hline & Mean & $S D$ & Mean & $S D$ & Mean & $S D$ & \\
\hline Impact peak (BW) & 2.02 & 0.42 & 1.83 & 0.41 & 1.62 & 0.40 & \\
\hline Time to impact peak (ms) & $53.58 A$ & 30.47 & 21.45 & 7.09 & $41.94 A$ & 31.37 & * \\
\hline Average loading rate (BW/s) & $37.62 A$ & 23.75 & 85.36 & 42.75 & $38.66 A$ & 16.60 & * \\
\hline Instantaneous loading rate (BW/s) & $48.14 A$ & 23.47 & 179.09 & 80.70 & $50.73 A$ & 25.46 & * \\
\hline Tibial acceleration (g) & $4.81 A$ & 2.93 & 8.45 & 4.33 & $4.33 A$ & 1.59 & * \\
\hline Time to tibial acceleration (ms) & $45.70 A$ & 54.25 & 24.00 & 7.38 & $56.97 A$ & 51.65 & * \\
\hline Tibial acceleration slope (g/s) & $226.72 A$ & 146.51 & 422.28 & 252.55 & $182.57 A$ & 83.08 & * \\
\hline
\end{tabular}

Notes: ${ }^{*}=$ significant main effect.

$A=$ Significantly different from minimalist footwear
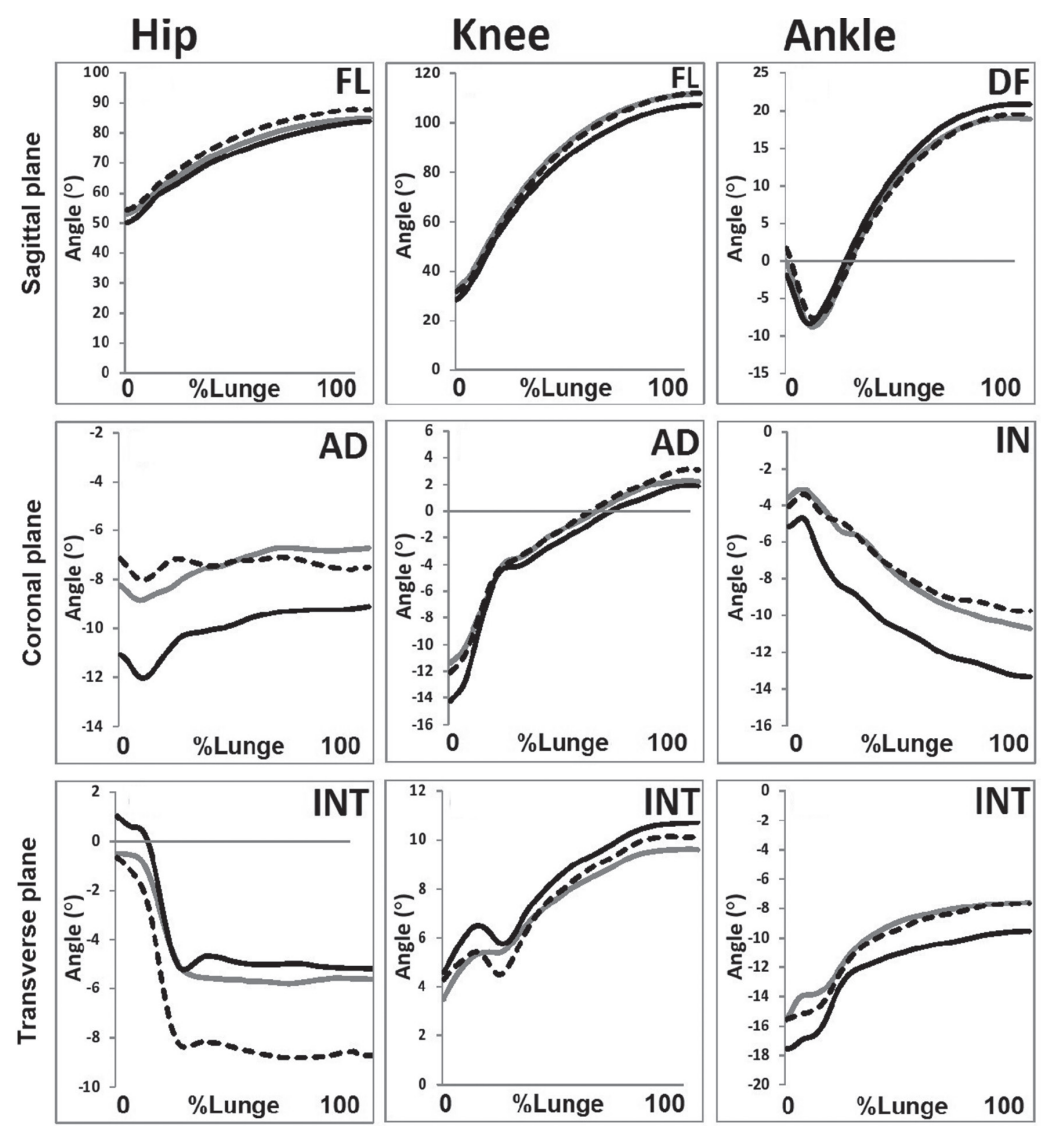

Figure 1. Hip, knee and ankle joint kinematics as a function of footwear (black = minimalist, grey = squash-specific, dash = running shoe $),(F L=$ flexion, $D F=$ dorsiflexion, $A D=$ adduction, $I N=$ inversion, $I N T=$ internal).

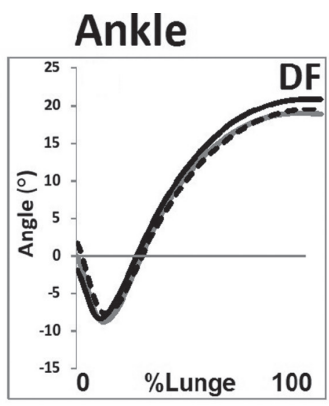

footwear compared to the squash $(\mathrm{p}=.001)$ and running $(\mathrm{p}=.001)$ footwear. There was also a significant main effect $\left(\mathrm{F}_{(2,22)}=9.25, \mathrm{p}<.05, \mathrm{p} \eta^{2}=\right.$ 0.48 ) for the time to peak tibial acceleration. Post-hoc analysis showed that time to peak tibial acceleration was significantly shorter in the minimalist footwear compared to the squash $(p=.03)$ and running $(p=.01)$ footwear. Finally a significant main effect $\left(\mathrm{F}_{(2,22)}\right.$ $\left.=10.73, \mathrm{p}<.05, \mathrm{p \eta}^{2}=0.52\right)$ was shown for tibial acceleration slope. Post-hoc analysis showed that tibial acceleration slope was significantly greater in the minimalist footwear compared to the squash $(p=.004)$ and running $(p=.006)$ footwear.

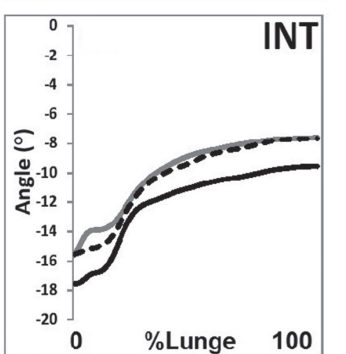

\section{Kinematics}

Hip

No significant $(\mathrm{p}>05)$ differences were observed between footwear.

Knee

No significant $(\mathrm{p}>.05)$ differences were observed between footwear.

Ankle

No significant $(p>05)$ differences were observed between footwear. 
Table 2. Hip joint kinematics as a function of footwear

\begin{tabular}{|c|c|c|c|c|c|c|}
\hline & \multicolumn{2}{|c|}{ Running shoe } & \multicolumn{2}{|c|}{ Minimalist } & \multicolumn{2}{|c|}{ Squash footwear } \\
\hline & Mean & $S D$ & Mean & $S D$ & Mean & $S D$ \\
\hline \multicolumn{7}{|l|}{ Sagittal plane } \\
\hline Angle at footstrike $\left({ }^{\circ}\right)$ & 54.25 & 25.86 & 50.06 & 27.76 & 52.88 & 29.21 \\
\hline Peak flexion $\left({ }^{\circ}\right)$ & 88.32 & 29.19 & 83.83 & 31.92 & 84.86 & 31.23 \\
\hline Relative range of motion $\left(^{\circ}\right)$ & 34.06 & 10.90 & 33.77 & 11.22 & 31.98 & 10.92 \\
\hline \multicolumn{7}{|l|}{ Coronal plane } \\
\hline Angle at footstrike $\left({ }^{\circ}\right)$ & -7.13 & 10.73 & -11.06 & 8.86 & -8.23 & 9.53 \\
\hline Peak abduction $\left({ }^{\circ}\right)$ & -11.68 & 9.55 & -14.74 & 9.14 & -11.34 & 8.98 \\
\hline Relative range of motion $\left({ }^{\circ}\right)$ & 4.55 & 4.87 & 3.68 & 4.11 & 3.10 & 3.37 \\
\hline \multicolumn{7}{|l|}{ Transverse plane } \\
\hline Angle at footstrike $\left({ }^{\circ}\right)$ & -0.64 & 11.22 & 1.04 & 7.17 & -0.49 & 8.85 \\
\hline Peak external rotation $\left({ }^{\circ}\right)$ & -11.20 & 12.84 & -8.41 & 8.53 & -8.25 & 9.61 \\
\hline Relative range of motion $\left({ }^{\circ}\right)$ & 10.55 & 4.51 & 9.45 & 6.07 & 7.77 & 4.72 \\
\hline
\end{tabular}

Table 3. Knee joint kinematics as a function of footwear

\begin{tabular}{|c|c|c|c|c|c|c|}
\hline & \multicolumn{2}{|c|}{ Running shoe } & \multicolumn{2}{|c|}{ Minimalist } & \multicolumn{2}{|c|}{ Squash footwear } \\
\hline & Mean & $S D$ & Mean & $S D$ & Mean & $S D$ \\
\hline \multicolumn{7}{|l|}{ Sagittal plane } \\
\hline Angle at footstrike $\left({ }^{\circ}\right)$ & 31.84 & 13.23 & 28.52 & 9.96 & 32.93 & 10.86 \\
\hline Peak flexion $\left({ }^{\circ}\right)$ & 112.08 & 14.64 & 107.30 & 16.93 & 111.74 & 15.68 \\
\hline Relative range of motion $\left({ }^{\circ}\right)$ & 80.24 & 19.00 & 78.78 & 20.71 & 78.82 & 22.64 \\
\hline \multicolumn{7}{|l|}{ Coronal plane } \\
\hline Angle at footstrike $\left({ }^{\circ}\right)$ & 4.29 & 6.68 & 4.58 & 5.38 & 3.48 & 5.76 \\
\hline Peak adduction $\left({ }^{\circ}\right)$ & 12.07 & 8.63 & 12.28 & 8.14 & 11.27 & 9.04 \\
\hline Relative range of motion $\left({ }^{\circ}\right)$ & 7.78 & 6.83 & 7.70 & 6.64 & 7.79 & 7.07 \\
\hline \multicolumn{7}{|l|}{ Transverse plane } \\
\hline Angle at footstrike $\left({ }^{\circ}\right)$ & -12.13 & 5.61 & -14.28 & 5.73 & -11.44 & 6.97 \\
\hline Peak internal rotation $\left({ }^{\circ}\right)$ & 3.98 & 7.46 & 2.66 & 8.01 & 3.29 & 7.35 \\
\hline Relative range of motion $\left({ }^{\circ}\right)$ & 16.11 & 8.93 & 16.95 & 9.36 & 14.73 & 10.04 \\
\hline
\end{tabular}

Table 4. Ankle joint kinematics as a function of footwear

\begin{tabular}{|c|c|c|c|c|c|c|}
\hline & \multicolumn{2}{|c|}{ Running shoe } & \multicolumn{2}{|c|}{ Minimalist } & \multicolumn{2}{|c|}{ Squash footwear } \\
\hline & Mean & $S D$ & Mean & $S D$ & Mean & $S D$ \\
\hline \multicolumn{7}{|l|}{ Sagittal plane } \\
\hline Angle at footstrike $\left({ }^{\circ}\right)$ & 1.68 & 6.44 & -1.83 & 8.34 & -0.05 & 5.70 \\
\hline Peak dorsiflexion $\left({ }^{\circ}\right)$ & 19.75 & 9.75 & 21.04 & 9.25 & 19.24 & 4.88 \\
\hline Relative range of motion $\left({ }^{\circ}\right)$ & 18.07 & 10.02 & 22.86 & 9.45 & 19.28 & 8.17 \\
\hline \multicolumn{7}{|l|}{ Coronal plane } \\
\hline Angle at footstrike $\left({ }^{\circ}\right)$ & 0.65 & 3.34 & 2.46 & 4.25 & 1.00 & 4.52 \\
\hline Peak eversion $\left({ }^{\circ}\right)$ & -7.99 & 5.27 & -6.42 & 4.17 & -8.60 & 5.29 \\
\hline Relative range of motion $\left({ }^{\circ}\right)$ & 8.64 & 5.22 & 8.88 & 5.26 & 9.60 & 4.68 \\
\hline \multicolumn{7}{|l|}{ Transverse plane } \\
\hline Angle at footstrike $\left({ }^{\circ}\right)$ & 0.34 & 5.39 & -1.39 & 3.91 & 0.78 & 5.66 \\
\hline Peak internal rotation $\left({ }^{\circ}\right)$ & 2.35 & 6.17 & -0.10 & 4.48 & 2.64 & 6.09 \\
\hline Relative range of motion $\left({ }^{\circ}\right)$ & 2.01 & 1.54 & 1.30 & 0.96 & 1.86 & 1.16 \\
\hline
\end{tabular}




\section{Discussion and conclusions}

The current investigation aimed to determine the effects of different footwear on the kinetics and kinematics of the squash lunge. This is the first study to examine the biomechanics of squash lunge movement in different squash footwear. The findings from this work may provide important information to squash players regarding the selection of appropriate footwear.

The first key observation from the current work is that vertical loading rate and tibial acceleration parameters were significantly larger in the minimalist footwear. This finding supports our hypothesis and also the findings of Sinclair et al. (2015) who showed that minimalist footwear were associated with significant increases in impact loading in comparison to netball court-specific footwear. This finding may have clinical relevance as excessive impact loading that is experienced too frequently has been implicated in the aetiology of chronic injuries in athletic populations (Whittle, 1999). This therefore indicates that squash players who play using minimalist footwear may increase their risk of overuse injury occurrence associated with excessive impact loading in relation to the squash-specific and running shoes. It is hypothesized that this result is a function of the increased shoe midsole interface found in the squash-specific and running footwear. Impact loading magnitude is determined by the rate at which the momentum of the foot changes (Whittle, 1999); therefore, a larger midsole interface, as found in the squash-specific footwear and running footwear, would serve to reduce the impact magnitude.

Importantly, participants from the current investigation showed a significant preference towards the running shoes. This finding disagrees with those presented by both Geil (2002), Sinclair et al. (2015) and Shorter, Lake, Smith, and Lauder, (2011) who found preferences for minimalist footwear in different sports. This may be due to the high impact nature of the lunge; due to this the squash players might have selected the footwear with the highest level of comfort, i.e. the running shoes. A potential drawback regarding this finding is that the participants did not habitually wear minimalist footwear and thus there may have been a bias not only in the subjective preferences. It is therefore advised that the current investigation to be repeated using squash players who habitually wear minimalist footwear.
Of further importance to the current study is the finding that there were no significant alterations in lower extremity kinematics as a function of the experimental footwear. Different footwear has been shown to alter the movement patterns during submaximal disciplines such as running, due to the proprioceptive effects of different cushioning systems (Sinclair, et al., 2013a). However, it is proposed that the lack of kinematic differences in this investigation relates to the explosive nature of the lunge movement where the proprioceptive influence of different cushioning has less influence on the resultant movement pattern. Overall, this indicates, from an aetiological perspective, that different footwear may not influence squash players susceptibility to chromic injuries caused by malalignment of the lower extremity segments.

A limitation of the current investigation is that only male squash players were examined. Sinclair and Bottoms (2013) demonstrated that lunge kinematics differ as a function of gender, therefore the results from this study may not be generalizable to female squash players. It is recommended that future work should repeat this experiment design using a female sample. A further potential drawback is that only the lunge movement was examined. This was undertaken as the lunge represents the highest impact squash movement and thus exposes the musculoskeletal system to the highest level of impact loading. However, competitive squash also involves turning, running and side stepping. Therefore, it is recommended that future studies consider the influence of different footwear when performing different squash movements.

In conclusion, this investigation adds to the current knowledge by providing a comprehensive evaluation of the kinetics and kinematics of the lunge movement in squash players whilst using minimalist, squash-specific and running shoes. The significant increase in impact loading in the minimalist footwear suggests this type of shoe may place squash players at an increased risk for development of impact-related chronic injuries. The current study concluded therefore that the adoption of minimalist footwear for squash may not be advisable and continued utilization of squash-specific or traditional footwear is recommended. Future work should seek to expand the current investigation beyond the lunge movement.

\section{References}

Bell, A.L., Brand, R.A., \& Pedersen, D.R. (1989). Prediction of hip joint centre location from external landmarks. Human Movement Science, 8, 3-16.

Berson, B., Rolnick, A., Ramos, C. \& Thornton, J. (1981). An epidemiologic study of squash injuries. The American Journal of Sports Medicine, 9, 103-106. 
Bonacci, J., Saunders, P.U., Hicks, A., Rantalainen, T., Vicenzino, B.G.T., \& Spratford, W. (2013). Running in a minimalist and lightweight shoe is not the same as running barefoot: A biomechanical study. British Journal of Sports Medicine, 47, 387-392.

Bonacci, J., Vicenzino, B., Spratford, W., \& Collins, P. (2014). Take your shoes off to reduce patellofemoral joint stress during running. British Journal of Sports Medicine, 48, 425-428.

Cappozzo, A., Catani, F., Leardini, A., Benedeti, M.G., \& Della, C.U. (1995). Position and orientation in space of bones during movement: Anatomical frame definition and determination. Clinical Biomechanics, 10, 171-178.

Clavisi, O., \& Finch, C. (2000). Squash injury countermeasures: A review of the literature. Journal of Science and Medicine in Sport, 3, 13-22.

Cronin, J., McNair, P., \& Marshall, R. (2003). Lunge performance and its determinants. Journal of Sports Sciences, 21, 49-57.

Eime, R., Zazryn, T., \& Finch, C. (2003). Epidemiology of squash injuries requiring hospital treatment. Injury Control and Safety Promotion, 10, 243-245.

Finch, C., \& Eime, R. (2001). The epidemiology of squash injuries. International Journal of Sports Medicine, 2, 1-11.

Firminger, C. R., \& Edwards, W. B. (2016). The influence of minimalist footwear and stride length reduction on lowerextremity running mechanics and cumulative loading. Journal of Science and Medicine in Sport (In press).

Geil, MD. (2002). The role of footwear on kinematics and plantar foot pressure in fencing. Journal of Applied Biomechanics, 18, 155-162.

Meyer, L., van Niekerk, L., Prinsloo, E., Steenkamp, M., \& Louw, Q. (2009). Prevalence of musculoskeletal injuries among adolescent squash players in the Western Cape. South African Journal of Sports Medicine, 19, 3-8.

Paquette, M. R., Zhang, S., \& Baumgartner, L. D. (2013). Acute effects of barefoot, minimal shoes and running shoes on lower limb mechanics in rear and forefoot strike runners. Footwear Science, 5, 9-18.

Shorten, M.R. (1993). The energetics of running and running shoes. Journal of Biomechanics, 26, 41-51.

Shorter, K., Lake, J., Smith, N., \& Lauder, M. (2011). Influence of the foot-floor interface on squatting performance. Portuguese Journal of Sport Sciences, 11, 385-388.

Sinclair, J., \& Bottoms, L. (2013). Gender differences in the kinetics and lower extremity kinematics of the fencing lunge. International Journal of Performance Analysis in Sport, 13, 440-451.

Sinclair, J., Bottoms, L., Taylor, K., \& Greenhalgh, A. (2010). Tibial shock measured during the fencing lunge: The influence of footwear. Sports Biomechanics, 9, 65-71.

Sinclair, J., Chockalingam, N., Naemi, R., \& Vincent, H. (2015). The effects of sport-specific and minimalist footwear on the kinetics and kinematics of three netball-specific movements. Footwear Science, 7, 31-36.

Sinclair, J., Greenhalgh, A., Edmundson, C.J., Brooks, D., \& Hobbs, S.J. (2013a). The influence of barefoot and barefoot-inspired footwear on the kinetics and kinematics of running in comparison to conventional running shoes. Footwear Science, 5, 45-53.

Sinclair, J., Hobbs, S.J., Currigan, G., \& Taylor, P.J. (2013b). A comparison of several barefoot inspired footwear models in relation to barefoot and conventional running footwear. Comparative Exercise Physiology, 9, 13-21.

Sinclair, J., McCarthy, D., Bentley, I., Hurst, H.T., \& Atkins, S. (2015). The influence of different footwear on 3-D kinematics and muscle activation during the barbell back squat in males. European Journal of Sport Science, $15,583-590$.

Squadrone, R, \& Gallozzi., C. (2009). Biomechanical and physiological comparison of barefoot and two shod conditions in experienced barefoot runners. Journal of Sports Medicine and Physical Fitness, 49, 6-13.

Stacoff, A., Denoth, J., Kaelin, X., \& Stuessi, E. (1988). Running injuries and shoe construction: Some possible relationships. International Journal of Sport Biomechanics, 4, 342-357.

Vuckovic, G., \& James, N. (2010). The distance covered by winning and losing players in elite squash matches. Kinesiologia Slovenica, 16, 44-50.

Whittle, M.W. (1999). The generation and attenuation of transient forces beneath the foot: A review. Gait \& Posture, $10,264-275$.

Submitted: May 14, 2015

Accepted: February 28, 2017

Published Online First: September 27, 2017

Correspondence to:

Jonathan Sinclair

Centre for Applied Sport and Exercise Sciences

School of Sport Tourism and Outdoors

University of Central Lancashire

Preston, Lancashire, PR1 2HE.

E-mail: jksinclair@uclan.ac.uk 